\title{
Intussusception of the vermiform appendix
}

\author{
Richard A Dickson-Lowe, ${ }^{1}$ Sherine Ibrahim, ${ }^{1}$ Lamios Munthali, ${ }^{2}$ Fazal Hasan ${ }^{3}$
}

${ }^{1}$ Department of General Surgery, Tunbridge Wells Hospital, Tunbridge Wells, UK ${ }^{2}$ Department of Histopathology, Maidstone and Tunbridge Wells NHS Trust, Tunbridge Wells, Kent, UK ${ }^{3}$ Department of Emergency Surgery, Maidstone and Tunbridge Wells NHS Trust, Tunbridge Wells, Kent, UK

\section{Correspondence to} Richard Alexander DicksonLowe, richarddickson-lowe@ doctors.org.uk

Accepted 29 January 2015

\begin{abstract}
SUMMARY
Appendicitis is a common presentation to an acute general surgical on call team. It can be a difficult diagnosis at times, particularly in sexually active young women, in whom it is often surgically challenging. This case is of a relatively straightforward diagnosis, taken for laparoscopic appendicectomy that resulted in performing an open right hemicolectomy for a necrotic, intussuscepted appendix. Histology ultimately revealed the cause of intussusception and resultant infarction of the appendix to be endometriosis.
\end{abstract}

\section{BACKGROUND}

Appendicitis is a common presentation, but an intussuscepted appendix is uncommon, with an incidence of $0.01 \%,{ }^{1}$ and is commonly found at the time of operation. The coincidence of endometriosis is even more rare with only very few published cases.

\section{CASE PRESENTATION}

A 36-year-old woman began to experience vague periumbilical pain and diarrhoea early one Saturday morning, which she put down to a stressful week, eating late and period pains. However, she had not experienced similar period pains before. On reflection, she recalled feeling a 'pop' in her abdomen on the previous (Friday) evening. The pain continued over the weekend, being relieved by passing stool. On Sunday the pain worsened and vomiting started. National Health Service direct advised an emergency doctor's appointment, when appendicitis was suspected and a surgical admission to hospital was arranged.

Initial observations in hospital showed a temperature of $38.5^{\circ}$, a regular pulse of $86 \mathrm{bpm}$, blood pressure of $142 / 87 \mathrm{~mm} \mathrm{Hg}$, respiratory rate of $18 \mathrm{bpm}$ and oxygen saturations of $96 \%$ on room air. Abdominal examination revealed lower abdominal pain on deep palpation (greatest in the right iliac fossa) with guarding and percussion tenderness. There was no rebound tenderness and no Rovsing's or psoas sign.

She has no significant medical history, does not take medication, has no family history of gastrointestinal cancer or endometriosis. She smokes 10 cigarettes a day and drinks less than 14 units of alcohol per week.

\section{INVESTIGATIONS}

A urine dipstick showed only blood (currently menstruating) with a negative $\beta$-human chorionic gonadotropin (for pregnancy). Blood tests showed haemoglobin $(\mathrm{Hb}) 139 \mathrm{~g} / \mathrm{L}$, white cell count (WCC) $13.7 \times 10^{9} / \mathrm{L}$, neutrophils $10.17 \times 10^{9} / \mathrm{L}, \mathrm{C}$ reactive protein (CRP) 26, normal urine and electrolytes (U\&Es), normal liver function tests (LFTs), normal clotting and a normal amylase.

Ultrasound scan was considered but it was felt that this would not change the eventual management, which was for diagnostic laparoscopy +/appendicectomy.

\section{DIFFERENTIAL DIAGNOSIS}

A 36-year-old menstruating woman, with a short history of fevers, diarrhoea and vomiting with lower abdominal pain could have a multitude of diagnoses. These would include bowel (gastroenteritis, inflammatory bowel disease, appendicitis), bladder (stones, infection) and gynaecological (ectopic pregnancy, ovarian cysts, endometriosis, infection).

\section{TREATMENT}

After $12 \mathrm{~h}$ of observation by the general surgical team, the patient was taken to theatre for laparoscopy. Ports were placed (size 10 umbilical port, size 5 suprapubic port and size 5 left lower quadrant port) for a standard laparoscopic appendicectomy. The caecum was found to be adherent to the right salpinx/fimbriae and to the peritoneum over the iliac vessels and psoas muscle. The caecum came away with gentle blunt dissection and revealed the ileocaecal fold of Treves, but no appendix was visible. The peritoneum was then dissected to view retrocaecally (the posterior caecum), in search of the appendix. After visualising the whole caecum without seeing the appendix, the operation was converted to an open procedure. A gridiron approach was made and the caecum delivered, revealing a mass inside the caecum, believed to be the appendix. It was not possible to evert the appendix from its orifice, and was only causing trauma to the caecum. Therefore, a limited right hemicolectomy (caecectomy) was performed. Following the operation, the specimen was opened to reveal the necrotic, intussuscepted appendix (figure 1).

\section{OUTCOME AND FOLLOW-UP}

The patient made a good recovery in the days following the operation, without any complications. She has had loose stool since the operation, which is common in patients following a right hemicolectomy. She was discharged from hospital happy with her care, without the need for further follow-up by the general surgical team.

\section{DISCUSSION}

Appendicitis is the most common surgical emergency in general surgery. General lifetime risk is approximately $8.5 \%$ in men and $6.5 \%$ in women. ${ }^{2}$ It affects 35000 patients every year in England. ${ }^{2}$ 


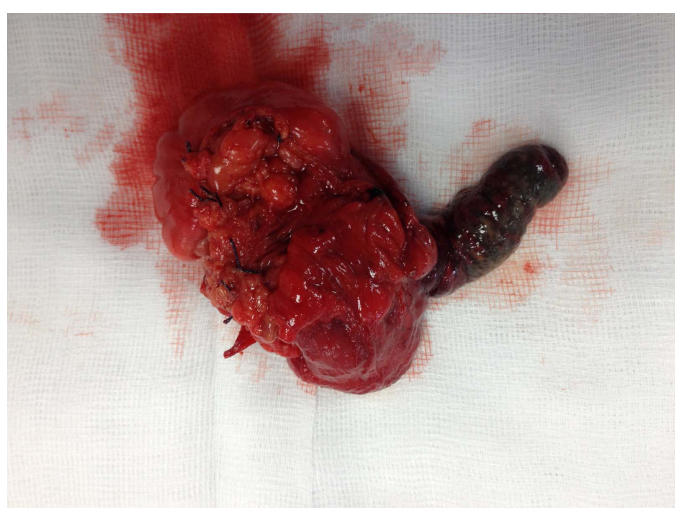

Figure 1 Necrotic, intussuscepted appendix (caecum is laid open and everted to reveal appendix).

Male-female ratio is $1.4: 1$. It is most common in second and third decades of life with peak incidence being age $10-19 .^{3}$ Appendicitis is often related to obstruction of the appendix lumen, due to follicular hyperplasia (initiated or exacerbated by viral or bacterial infection) in young patients, and to fibrosis, faecoliths (often due to constipation or fruit stones), or neoplasia (carcinoid or caecal carcinoma) in the older population. ${ }^{4}$

Endometriosis is defined as the proliferation and function of endometrial tissue outside the endometrial cavity. ${ }^{5}$ Reported incidence in premenopausal women is $8-15 \% .^{5}$ Although the disease classically involves the pelvic organs and pelvic peritoneum, seeding has been observed elsewhere. If suspected or seen during laparoscopy, this can be confirmed with biopsy sent to the histopathology laboratory for immunostaining. Normal H\&E staining (a standard histopathology stain), will show up endometriosis well (figure 2). However, endometriosis will be estrogen receptor (ER) positive, while the rest of the appendix tissue will be ER negative, thus is much better viewed and confirmed with staining (figure 3).

The aetiology of endometriosis is unknown and pathogenesis has been described by the transportation theory and the metaplastic theory. The transportation theory presumes that endometrial cells are transported to distant cites by surgical manipulation, menstrual shedding via the fallopian tubes or by lymphatic and vascular spread. The metaplastic theory suggests that embryonic coelomic mesothelium differentiates into endometrial tissue in response to inflammation or trauma. ${ }^{6}$ The most common symptoms of endometriosis are dysmenorrhoea, pelvic pain and infertility, but patients can also be asymptomatic.

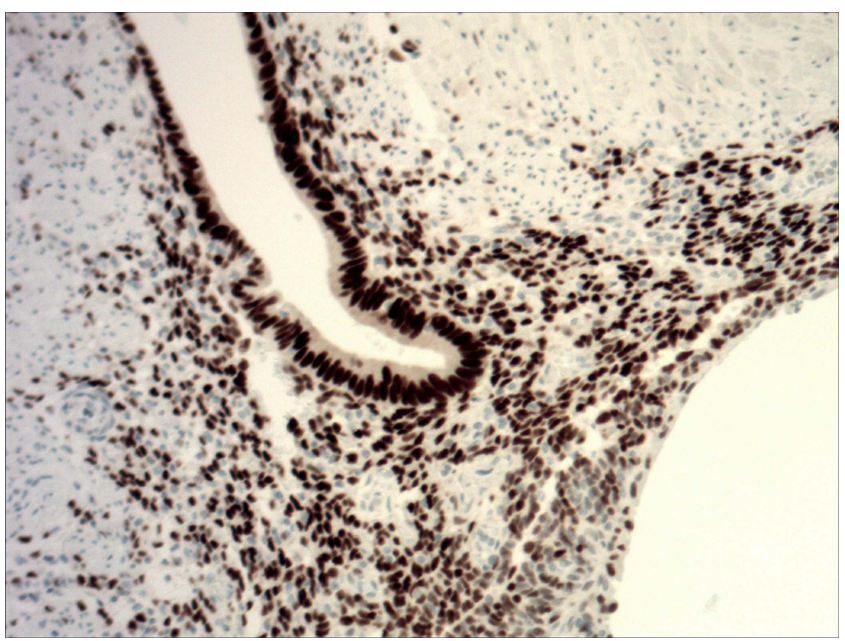

Figure 3 Estrogen receptor positive immunostaining in endometriosis showing glands and stroma.

Incidence of gastrointestinal endometriosis varies between 3\% and $37 \%$ in those women who have proven disease. ${ }^{5}$ Rectum and sigmoid are most commonly involved, followed by rectovaginal septum, small intestine, caecum and appendix. It usually takes the form of small, serosal, asymptomatic deposits. Under cyclical hormone influences these deposits may proliferate and infiltrate the bowel wall or the appendix. ${ }^{7}$

Appendiceal endometriosis is usually asymptomatic, but when symptomatic it presents as appendicitis. Acute appendiceal inflammation arises because of partial or complete luminal occlusion by the endometriosis, which has invaded the full thickness of the wall. Appendiceal intussusception secondary to endometriosis is extremely rare with fewer than 30 cases being reported over the past 50 years. ${ }^{5}$ Faecoliths have also been reported to cause intussusception of the appendix. ${ }^{8}$ Endometrial involvement of the appendix is usually accompanied by chronic fibrosis, inflammation and hypertrophy or hyperplasia of the muscularis propria (figure 4). This hyperplastic/hypertrophic segment serves as a lead point for hyperperistalsis, which makes that part of the appendix prone to intussusception. When this is combined with a fully mobile appendix that has a wide proximal lumen and a fat-free mesoappendix, intussusception is even more likely. ${ }^{5} 7$

In suspected situations, hospital admission for 12-24 h observation is a safe and effective approach. ${ }^{9}$ No single laboratory test or combination of tests have been shown to be as accurate as the careful examination and clinical acumen of an

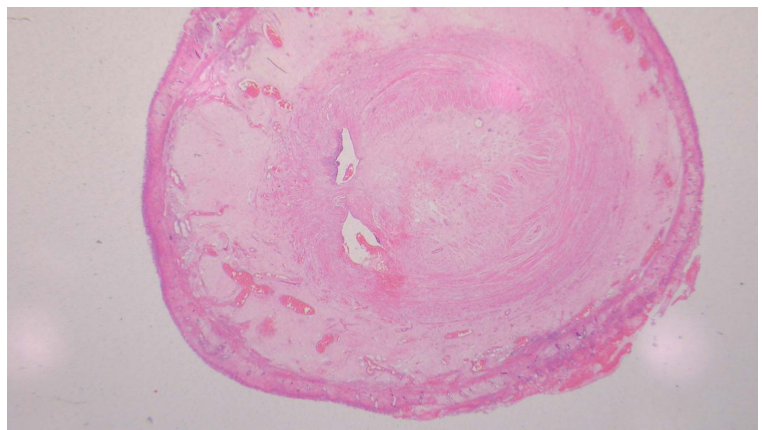

Figure 4 H\&E stain (a common histopathological stain): transverse section of appendix showing intussusception. Mucosa is at the periphery and serosa is at the centre (reverse order as expected for intussusception).

Figure 2 H\&E stain: high-power magnification of endometriosis. 
experienced surgeon. ${ }^{10}{ }^{11}$ Nevertheless, laboratory tests are useful adjuncts to the surgeon's clinical impression, particularly in high-risk patients and those with equivocal clinical presentation. A pregnancy test, as always, is mandatory in women of childbearing age. Performing a urinalysis that yields positive results can be confusing, as microscopic haematuria and pyuria can occur in acute appendicitis due to the proximity to the ureter and bladder. Leucocytosis (raised WCC) is present in 70$92 \%$ of cases but up to one-third of patients with acute appendicitis will have a normal WCC. CRP has a sensitivity of 93\%, specificity of $80 \%$ and accuracy of $91 \%$, and is recommended by many authors in all cases. ${ }^{12}$

Imaging should only be performed in equivocal cases. It is neither cost-effective nor helpful when there is a high or a low probability of acute appendicitis. The best radiological test for acute appendicitis is a CT of the abdomen and pelvis. CT scan will show a thickened wall ( $>2 \mathrm{~mm})$, appendicolith ( $25 \%$ cases), concentric thickening of inflamed appendiceal wall, fat stranding, phlegmon, abscess or free fluid. ${ }^{13}$ An ultrasound scan in experienced hands can be useful in diagnosing acute appendicitis in equivocal cases and in detecting pelvic pathologies in women, but usefulness in an intussuscepted appendix is not reported. Acute appendicitis presents as a non-compressible tubular structure at the base of the caecum, thickened wall $(>2 \mathrm{~mm}$ ), luminal distension (diameter $>6 \mathrm{~mm}$ ) and free fluid in the pelvis in some cases. ${ }^{13}$ There are reported cases where a 'mass' has been seen in the caecum and further colonoscopic investigation has been performed. In these circumstances, colonoscopy has unveiled the diagnosis and, occasionally, therapeutic procedures have been performed to remove the intussuscepted appendix successfully. ${ }^{14} 15$

As a final note, diagnostic laparoscopy should be viewed as an invasive procedure requiring general anaesthetic. If no other pathology is identified, for example, Crohn's disease or Meckel's diverticulum, or tubo-ovarian pathology, the appendix should be removed regardless of its gross appearance. ${ }^{16}$ This approach is not a gold standard, and surgical preference based on anecdotal evidence and experience is taken. However, this approach (taken by many) rules out inflammation by pathological examination and makes the diagnosis of acute appendicitis less likely if the patient reports similar pain in the future.

\section{Patient's perspective}

The patient was asked by the surgical team for her opinions about these events and was, in the main, positive about her experience. She was initially shocked on waking up after the operation to find a lower midline laparotomy scar (which was explained during the consent process). However, once the surgical team had explained the findings to her she was reassured that the most appropriate course of action had been undertaken.

\section{Learning points}

As in all cases of intussusception, the index of suspicion must be high, as $90 \%$ of all intussusceptions in adults are due to an underlying neoplastic process.

- Intestinal endometriosis should be considered as a differential diagnosis in postmenarchal women who present with episodic gastrointestinal symptoms, particularly in conjunction with gynaecological symptoms.

- The gold standard investigation, considering other case reports, would appear to point towards laparoscopy followed by surgical resection in order to obtain histological evidence as to the lead point/cause of intussusception.

Contributors LM was involved in significant input into the histopathology and review of the article. FH was the consultant in charge of the patient's care, and has reviewed and overseen the article being written.

Competing interests None.

Patient consent Obtained.

Provenance and peer review Not commissioned; externally peer reviewed.

\section{REFERENCES}

1 Collins D. 71,000 Human appendix specimens. A final report summarising forty years' study. Am J Proctol 1963;14:265-81.

2 Humes D, Speake WJ, Simpson J. Appendicitis. BMJ Clin Evid 2007;12:408.

3 Addiss DG, Shaffer N, Fowler BS, et al. The epidemiology of appendicitis and appendicectomy in the United States. Am J Epidemiol 1990;132:910-25.

4 Hardin DM Jr. Acute appendicitis: review and update. Am Fam Physician 1999;60:2027-34.

5 ljaz S, Lidder S, Mohamid W, et al. Intussusception of the appendix secondary to endometriosis: a case report. J Med Case Rep 2008;2:12.

6 Hasegawa T, Yoshida K, Matsui K. Endometriosis of the appendix resulting in perforated appendicitis. Case Rep Gastroenterol 2007;1:27-31.

7 Cameron IC, Rogers S, Collins MC, et al. Intestinal endometriosis. Int J Colorect Dis 1995; 10:83-6.

8 Ito J, Soeno T, Koizumi R. Intussusception of the appendix with a calcified faecolith. Jpn J Surg 1987;17:195-8.

9 Morris PJ, Wood WC. Chapter 27. Oxford textbook of surgery. 2nd edn. Oxford. Oxford University Press, 2000

10 Anderson BR, Kallehave FL, Anderson HK. Antibiotics versus placebo for the prevention of post-operative infection after appendicectomy. Cochrane Database Syst Rev 2005;(3):CD001439.

11 Sauerland A, Lefering R, Neugebauer EA. Laparoscopic versus open surgery for suspected appendicitis. Cochrane Database Syst Rev 2004;(4):CD001546.

12 Eriksson S, Granstrom L, Carlstrom A. The diagnostic value of repetitive preoperative analyses of C-reactive protein and total leucocyte count in patients with suspected acute appendicitis. Scand J Gastroenterol 1994;29:1145-9.

13 Jeffrey RB Jr, Laing FC, Townsend RR. Acute appendicitis: sonographic criteria based on 250 cases. Radiology 1988;167:327-9.

14 Pohl J. Intussusception of the appendix. Video Journal and Encylopedia of GI Endoscopy 2013;1:377.

15 Duncan JE, DeNobile JW, Sweeney WB. Colonoscopic diagnosis of appendiceal intussusception: case report and review of the literature. JSLS 2005;9: 488-90.

16 Grunewald B, Keating J. Should the 'normal' appendix be removed at operation for appendicitis? J R Coll Surg Edinb 1993;38:158-60. 


\section{Rare disease}

Copyright 2015 BMJ Publishing Group. All rights reserved. For permission to reuse any of this content visit http://group.bmj.com/group/rights-licensing/permissions.

BMJ Case Report Fellows may re-use this article for personal use and teaching without any further permission.

Become a Fellow of BMJ Case Reports today and you can:

- Submit as many cases as you like

- Enjoy fast sympathetic peer review and rapid publication of accepted articles

- Access all the published articles

- Re-use any of the published material for personal use and teaching without further permission

For information on Institutional Fellowships contact consortiasales@bmjgroup.com

Visit casereports.bmj.com for more articles like this and to become a Fellow 